\title{
Psychedelics: A New Treatment Paradigm in Psychiatry?
}

\author{
Author \\ Gerhard Gründer \\ Affiliation \\ Department of Molecular Neuroimaging, Central Institute of Mental \\ Health, Medical Faculty Mannheim, University of Heidelberg, \\ Mannheim, Germany \\ received 25.05 .2021 \\ revised 25.05 .2021 \\ accepted 26.05.2021 \\ published online $\quad 24.06 .2021$ \\ Bibliography \\ Pharmacopsychiatry 2021; 54: 149-150 \\ DOI 10.1055/a-1520-5020 \\ ISSN $\quad 0176-3679$ \\ (c) 2021. Thieme. All rights reserved. \\ Georg Thieme Verlag KG, Rüdigerstraße 14, \\ 70469 Stuttgart, Germany
}

\author{
Correspondence \\ Gerhard Gründer \\ Department of Molecular Neuroimaging, \\ Central Institute of Mental Health \\ 68159 Mannheim \\ Germany \\ gerhard.gruender@zi-mannheim.de
}

$\mathrm{J} 5$
The renaissance of psychedelics has accelerated further over the past year. At least that's true if you follow the public press. The New York Times recently titled "The Psychedelic Revolution Is Coming. Psychiatry May Never Be the Same.” on its front page [1]. The newspaper even stated that "psilocybin and MDMA are poised to be the hottest new therapeutics since Prozac." Prozac (fluoxetine) changed the practice of psychiatry worldwide when it was approved as the first selective serotonin inhibitor in 1987 in the USA. Many newspapers and online portals around the world blew the same horn. The enthusiastic headlines followed 2 publications in renowned medical journals. A paper in Nature Medicine demonstrated the superiority of 3,4-methylendioxy-N-methylamphetamine (MDMA) over placebo, administered in conjunction with manualized psychotherapy, in 90 patients with post-traumatic stress disorder (PTSD) [2]. The effect size was large (0.91). The sponsor of the study, the Multidisciplinary Association for Psychedelic Studies (MAPS), which had received "breakthrough status" for MDMA in PTSD by the Food and Drug Administration (FDA), expects approval for the compound in that indication as early as 2023 . The second paper that gained worldwide attention had been published just a few weeks earlier in the New England Journal of Medicine. Researchers from Imperial College London documented a numerically, but not statistically, larger decrease in depression self-rating scale scores in 30 patients treated with psilocybin compared to 29 patients treated with the reference antidepressant escitalopram [3]. Although the study was seemingly underpowered and has several other methodological limitations, it underscores the hope that psilocybin could be an effective and completely novel therapy for depression. Two large ongoing studies with three-digit patient numbers, one international multicentric (NCT03775200) and one German bicentric (NCT04670081), will provide conclusive evidence of whether psilocybin represents a real breakthrough treatment for depression. However, there are risks associated with the current euphoria, and some of the researchers who initiated the "psychedelic renaissance" about 15 years ago warn that it "could go off the rails" [4]. Only the responsible handling of these powerful substances and the careful scientific evaluation of their benefits and risks will prevent this. This special issue of Pharmacopsychiatry will discuss some of the multifaceted aspects of the use of psychedelics as treatments for psychiatric disorders.

It is important to be aware of the historical roots of our current medical practices. This is particularly true of the use of psychedelics for medical purposes. Nichols and Walter in their thoughtful review provide an overview of the historical basis on which all current psychedelic treatment research is based [5]. Treatment with a psychedelic is not just the application of a pill. Rather, it must always be embedded in psychotherapeutic support. The scope and nature of this psychotherapeutic program are the subjects of intense research, the current status of which is presented in the overview by Nayak and Johnson [6]. What is the mechanism of action of psychedelics? The entire spectrum of psychological and biological processes that are triggered by psychedelics is the subject of the review by Mertens and Preller [7]. They discuss the current state of research using the example of 2 possible future therapeutic indications, affective and substance use disorders. Finally, psychedelic therapy not only requires a new infrastructure in which it is carried out but also must be integrated into the existing system and differentiated from the recreational use of these substances. Many social, political, and cultural questions are affected by this enculturation. The challenges of how psychedelics could be implement- 
ed in a future mental health care system are discussed by Gründer and Jungaberle [8].

The editors of Pharmacopsychiatry are pleased to provide a stateof-the-art update of the current status of the use of psychedelics in psychiatry in this issue. The journal will certainly accompany the development of one of the most interesting subjects in psychiatry in the years to come.

\section{Conflict of Interest}

G. Gründer is co-founder and CEO of OVID Health Systems, Berlin.

\section{References}

[1] The New York Times. The psychedelic revolution is coming. Psychiatry may never be the same. 2021; https://www.nytimes.com/2021/05/09/ health/psychedelics-mdma-psilocybin-molly-mental-health.html (accessed on May $21^{\text {st }}, 2021$ )
[2] Mitchell JM, Bogenschutz M, Lilienstein A et al. MDMA-assisted therapy for severe PTSD: A randomized, double-blind, placebo-controlled phase 3 study. Nat Med 2021; doi:10.1038/s41591-021-01336-3

[3] Carhart-Harris R, Giribaldi B, Watts $R$ et al. trial of psilocybin versus escitalopram for depression. N Engl J Med 2021; 384: 1402-1411

[4] Yaden DB, Yaden ME, Griffiths RR. psychedelics in psychiatry-keeping the renaissance from going off the rails. J Am Med Assoc Psychiatry 2021; 78: 469-470

[5] Nichols DE, Walter $\mathrm{H}$. The history of psychedelics in psychiatry. Pharmacopsychiatry 2021; 54: 151-166. doi:10.1055/a-1310-3990

[6] Nayak S, Johnson MW. Psychedelics and psychotherapy. Pharmacopsychiatry 2021; 54: 167-175. doi:10.1055/a-1312-7297

[7] Mertens LJ, Preller KH. Classical psychedelics as therapeutics in psychiatry-current clinical evidence and potential therapeutic mechanisms in substance use and mood disorders. Pharmacopsychiatry 2021; 54: 176-190. doi:10.1055/a-1341-1907

[8] Gründer $G$, Jungaberle $H$. The potential role of psychedelic drugs in mental health care of the future. Pharmacopsychiatry 2021; 54 191-199. doi:10.1055/a-1486-7386 